\title{
pÿUrban spaces for intercultural encounters: teacher students reflections on the cultural plunge
}

\section{Posti-Ahokas, Hanna}

2015

Posti-Ahokas , H , Janhonen-Abruquah , H \& Johnson Longfor , R 2015 , ' Urban spaces for pÿintercultural encounters: teacher students reflections on the cultural plunge ', World Studies in Education, vol. 16 , no. 2 , pp. 45-55 . https://doi.org/10.7459/wse/16.2.05

http://hdl.handle.net/10138/231798

https://doi.org/10.7459/wse/16.2.05

acceptedVersion

Downloaded from Helda, University of Helsinki institutional repository.

This is an electronic reprint of the original article.

This reprint may differ from the original in pagination and typographic detail.

Please cite the original version. 


\title{
Urban spaces for intercultural encounters: teacher students' reflections on the cultural plunge
}

Hanna Posti-Ahokas, Hille Janhonen-Abruquah, Rita Johnson Longfor, University of Helsinki

This is a pre-print version of the article. To cite the article:

Posti-Ahokas, H., Janhonen-Abruquah, H. \& Longfor, R. 2015. Urban spaces for intercultural encounters: cultural plunges for future teachers. World Studies in Education, 16(2)45-55.

\begin{abstract}
The article reports on the experience of utilising urban spaces for intercultural encounters as part of a teacher education course on intercultural education in a Finnish University. The 'cultural plunges' - brief exposures to difference - reported in twenty two teacher students' reflective learning journals are analysed to understand how students' used experiential intercultural encounters for learning and for critical reflection. Suggestions are made both on the potential value and on the practical implementation of cultural plunges as part of the curriculum for intercultural education in teacher education.
\end{abstract}

Keywords: intercultural space, experiential learning, teacher education, cultural plunge, reflective learning journal

\section{Introduction}

The increased focus of teacher education on diversities and the demands for internationalising teacher education have challenged teacher educators in Finland to find new ways to enhance intercultural learning in teacher education. Increasing teacher students' exposure to intercultural encounters and incorporating these experiences into formal teacher education remains a challenge in the context of Finnish teacher education where diversities and social justice have often received minimal attention (see Dervin \& Keihäs, 2013). Previous research has shown that building upon teacher students' experiential knowledge of diversity and equity has been found to be critical to intercultural education (e.g. Dervin \& Hahl, 2014; King, Perez \& Shim, 2013; Houser, 2008; Nieto, 2006). In this article, we discuss the potential benefits of using brief intercultural encounters in 
urban spaces, known as 'the cultural plunge' (Houser, 2008; Nieto, 2006) as an educational activity for teacher students.

Connecting the study to the overall theme of the journal issue, the silent (or ignored) partner in our case is the out of educational premises environment of the city, the real life context. Teacher students' plunges into public urban spaces are analysed as examples of learning contexts aiming at providing teacher students with experiences of intercultural encounters beyond the class environment and linking learning occurring in school and out of school, thus paying specific attention to the spatiality of learning. The analysis contributes to the discussion on how to better link intercultural education to the real life and to the future work of teacher students. We discuss the experience of using cultural plunges into the urban spaces as a way to encourage teacher students to step outside their immediate comfort zone and to critically reflect on their intercultural encounters as part of a course on intercultural education that one of the authors taught in University of Helsinki in 2013 and in 2014.

Our analysis of students' experiences draws on students' reflective learning journals reporting on their cultural plunges. The analysis is framed around five different approaches to experiential intercultural learning (King, Perez \& Shim, 2013) that highlight the various dimensions and individual styles influencing learning. As a result, we will summarise the experience of using the cultural plunge and discuss the potential value of the approach, particularly in the context of Finnish teacher education.

\section{Experiential intercultural learning in the city}

Experiential learning focuses on learners' personal experiences and the ability to reflect upon them. The learner is responsible for her/his own learning and its outcomes. Learning is understood as an evolving process where knowledge, understanding and knowing are constantly reflected upon, 
questioned and re-constructed (Rauste-von Wright \& von Wright, 1997). Furthermore, the benefits of experiential learning are seen when thinking, feeling and doing are combined (Baker, 1989). In this study, while we focus on experiential learning and self-reflection, we also question how intercultural experiences can support learning especially in the context of teacher education.

As space is a complex social construction (Middleton, 2014) and often undermined in education, teacher educators need to be encouraged to use physical spaces, including the city, to support teacher students' learning. Cultural immersion, a form of experiential learning (e.g. Wilson, 1982) has been used in teacher education as a means to expose teacher students to diversities and thus enhance intercultural learning. As an example, experiences as varied as academic courses, study abroad immersion trips, service-learning programs, club activities and friendships have served as fertile ground for meaningful intercultural experiences for students (King et al., 2013). In a study on teacher education in the USA (Riggio, Sapolis \& Chen, 2011), students' critical thinking and problem solving skills were developed through 'real world education', referring to experiential learning through partnership with actors outside the University environment. By engaging with local NGOs' work, making films, arranging exhibitions and musical productions, students became involved directly with the surrounding city. They were encouraged to de-mystify the cultural other and to make the apparently exotic familiar by both academic studies and with a lived experience. These experiences prepared students for urbanised and globalised worlds by linking the academic domain with experiential learning (Riggio, Sapolis \& Chen, 2011).

The analyses by King et al. (2013) of college students' participation in various intercultural experiences highlighted five approaches that students frequently used, namely, (a) listen and observe, (b) compare and contrast ideas, (c) engage in personal reflection, (d) explore personal identity as it relates to intercultural understanding, and (e) empathise with others. These approaches display varying degrees of complexity as well as agency with which students engage their minds and their hearts. Notably, the practices deployed were often spontaneous rather than 
intentionally enacted by students regardless of the context of their intercultural experience. These five approaches are distinct from each other in that students used their cognitive and affective capacities to understand differences across cultures with varying degrees of complexity. In the study by King et al. (2013), students did not tend to limit their use of a given approach to a specific context. Thus, it seems that individuals' choice of approach appeared to be based on their cognitive and affective capacity to respond to the intercultural differences encountered during a particular experience, and that the capacity for deploying a range of approaches appears to vary with individual readiness to engage in intercultural experiences. Although King et al. (2013) emphasised students' positive emotions in promoting learning, it should equally be questioned how negative feelings could assist learning. In the context of this study, the city as a learning space offers a wide range of encounters that potentially evoke a variety of feelings. These previously reported experiences of incorporating experiential learning in higher education courses encouraged us to look for practices that could be included in teaching on intercultural within short University courses. In the following, we are introducing a more specific approach that was used in our present study.

Nieto (2006) and Houser (2008) have recommended cultural plunges - brief exposures to difference combined with personal reflection and group discussion - as effective means to increase teacher students' intercultural understanding. The approach involves brief exposure to social and cultural settings in which the student's norms are in the minority. Houser's (2008) analysis of the approach suggests that the cultural plunge fosters both critique and reflection and also enables questioning one's social milieus but also one's personal attitudes and actions. Therefore, the plunge can contribute to the enhancement of critical consciousness and multicultural understanding.

In Houser's (2008) study, the plunges consisted of three phases: 1) the initial plunge, 2) a written reflective account of the plunge, discussing it against literature and 3) group discussions 
on the experiences, insights gained and implications for teaching. For the initial plunge, students were asked to place themselves in a social situation, for usually between thirty minutes and two hours, in which their personal beliefs and/or actions were clearly in the minority. The 'plungers' encountered a wide range of experiences ranging from an 'able-bodied' student publicly dining with a paraplegic woman who had learned to eat with her feet to more superficial ones like visits to ethnic restaurants and reports from pre-planned vacation sites. In his application of the cultural plunge, Nieto (2006) asked students both to attend a religious service and to interact with homeless people or people with disabilities. Similarly, after the plunges, students wrote reflections focusing on stereotypes, emotional response and reactions and including discussion on how the plunge influenced stereotypical views and implications for future career.

Houser (2008) identified interrelated themes regarding the influence of the cultural plunge on student understanding. Many responded with courage to the social, emotional, and cognitive dissonance they encountered during the plunge. In their reflections in class and in written course assignments, students engaged themselves in social critique and critical reflection. Houser (2008) stressed the importance of the various phases of the cultural plunge that work together to impact learning and development. Beyond the actual encounter, preliminary planning, subsequent reflection, and substantive class discussion also contributed to the multicultural development of self. Those who gained the greatest understanding generally seemed to consider all aspects of the cultural plunge experience. The approach does also carry potential risks and limitations related to the variation in plunger's engagement and the ethical concerns raised from unequal power relations (Nieto, 2006; Houser, 2008). These limitations are discussed in more detail in the findings section.

\section{A study of teacher students' experiences of the cultural plunge}


The study on cultural plunges was conducted in connection with an intermediate level course on intercultural education at University of Helsinki, Department of Teacher education. The focus of the course (4ECTS) was on the interconnections of the education system and the teaching profession with the increasingly multicultural, rapidly changing society. The course consisted of lectures, group work, tutorials, independent work (including the cultural plunges), reading and writing of a learning journal and a literature essay. During the first lecture, the cultural plunge exercise was introduced. Students were asked to expose themselves to new things and/or meet new people according to their own interests and to report and reflect on at least three encounters in their learning journals. After submitting their written assignments, students were asked to sign a consent allowing their work to be used anonymously for research purposes. The data analysed for this study consists of twenty two teacher students' - both home students and exchange students, most in their early twenties' - reflective learning journals. Participating students were not given specific instructions on the length and nature of reporting and reflecting on the plunges. Therefore, the learning journals varied in length and the level of reflection. Reports from 32 plunges done into public, urban spaces were taken for a thematic analysis for this study.

\section{Findings}

Our analysis focused on 32 plunges into various urban spaces, including 1) shops, bars and restaurants (12 plunges), 2) museums and cultural centres (11 plunges) and 3) the streets and public transport (9 plunges). Analysing the teacher students' approaches used in the plunges, one or several of King's approaches (see King et al., 2013) could be identified. The most commonly used approach was 'compare and contrast' used in 18 plunges whereas 12 plunges were characterised by the 'listen and observe' approach. Reflection on personal identity was present only in 7 reported plunges. This may be due to the short duration of the plunges and of the course as a whole. Empathy or emotional aspects were reported in 6 plunges. The relatively low number under this 
category may be partly related to the reporting style used in the learning journals and the instructions given to teacher students. This may also explain the popularity of 'compare and contrast' approach that may be considered 'an academic' approach to reflecting on the plunges, rather than solely reporting on one's observations. Again, it is to be noted that the nature of assignment did not guide students towards any specific type of reporting and reflection.

The following sections examine examples of teacher students' reported plunges occurring in different types of public urban spaces. We depict how the city can provide opportunities for intercultural learning through observation and interaction with a diversity of people. The plunges introduced in more detail have been selected to represent the variety of experiences and approaches present in the learning journals. All examples presented here carry an element of surprise that characterises the experience of the plunger.

Spaces such as shops, gyms, bars and restaurants offered students with possibilities to engage in observations and informal discussions. Several plunges were actually done as part of teacher students' regular routines such as exercising. The plunge assignment seemed to help students to pay attention to the diversities in people around them and to take chances to learn more about themselves and the surrounding world. As an example, two Finnish students who worked in a shop and in a hotel reception told how they had given themselves a task of serving customers in a third language they rarely use. This had opened opportunities to interact on a new level with people and to reflect on their own relationships with their less used languages. The exercise had encouraged students to step outside their comfort zones and enter new kinds of spaces, like a dubious looking neighbourhood bar:

As entering the bar there was quite a big crowd hanging outside the bar. In the beginning we felt we were not able to fit in but entered anyway with an open mind. Soft reggae was played and the space looked like a comfortable living room. People of African background were sitting there as well as few white people. We sat by the door way and saw well when new people were entering the bar. Everyone greeted the bartender as they entered and many customers knew each other. -- Some greeted us as we sat by the door. The customers seemed quite friendly and there was a communal 
atmosphere. Many of them seemed to be regular customers. We stayed amongst us and chatted. I don't know if it had been different without my boyfriend being with us. The other customers might have started talking with us easier. But that would not matter; the place seemed quite open and friendly now. Warm atmosphere and sense of communality was created as the bartender dedicated a song with these words: "This song is for my niggas. My black niggas, my white niggas, all the niggas in the barenjoy!" Also new customers seemed to be welcomed and I will definitely go again. 2013_7_2 [written in Finnish, translation by authors]

The plunge shows the value of entering a new situation and facing one's anxieties. By listening and observing and through personal reflection one can reposition oneself in the new situation and modify perceptions about the space/place. Similarly in Nieto's (2006) study, students described the plunge experience as a progression of fear, excitement, and finally, appreciation. Realising how different the communities visited from what students had anticipated showed features of surprise and shock that resulted in high-impact experiences during the plunges. The plunges helped students to become aware of how little they know, resulting in some even feeling ashamed about their ignorance. A new desire to learn more about different groups was expressed. (Nieto, 2006). In our study, a similar type of fear or discomfort was reported on plunges occurring in the streets and in public transportation. These plunges were typically very brief and included interaction with strangers:

Conquering fears and talking to strangers can be really interesting and enriching. 2014_9_2 [journal written in English]

The initial excitement related to the plunges often turned into relief which in itself provided an element of surprise for the plungers. A language café organised in a coffee shop is presented as an example of intercultural space in between formal and informal:

Cafe Lingua is an event organised on Mondays in coffee shop xxx. Anyone interested in different languages, speaking them and learning more can join. -- On arrival people choose which language they want to speak and choose then the table by the flag. -- We decided to have an English speaking table where discussion would be based on our pre-set questions. -- After a moment five young women from different countries sat by our table. Three of them had come to Finland to study, one worked as an au-pair and the fifth one had come for professional development. We, the interviewers, were pleased to get so fast so many eager people to discuss. 
[Description of the content of conversation on cultural stereotypes and experiences of living in Finland] The interview situation was quite open and more like a discussion as the people had entered the coffee shop to join a conversation and to practice ones language skills. Taking part in Café Lingua was an exciting experience and we were surprised of how many people turned up eventually. I remember especially the positive and open atmosphere. People spoke gladly about themselves and used foreign languages. 2013_6_3 [journal written in Finnish, translation by authors]

The most surprising element for the Finnish teacher students who visited the language café as part of their studies was to see the informal set up creating a space to easily interact with new people. This enabled them to use various languages and to make friends outside one's immediate everyday environments. This plunge provided students with positive experiences and informal encounters with people from different parts of the world.

Plunges that were realised as excursions to public spaces such as museums and cultural centres helped students to reflect their pre-conceptions and to compare and contrast their prior knowledge against the new experiences. Students visited exhibitions, attended public discussion events or cultural events. In these plunges, the topic or the focus on attention was guided by students' interests in particular cultures or phenomena.

I decided to go to The Ateneum [The Finnish National Gallery] on a free entrance day- --There was a painting collection from the late 19th century and the early 20th century about several artists who decided to go away from the capital to develop their art skills and also find a better and nature place to live with their families -- the idea is that they moved there to have a more nature and calm experience, but for me Helsinki is a nature and calm city. Two thoughts about it, the human acts have much more in common that we think. In the Spanish culture also appeared that idea of countryside and life, all of them coming from the Latin locus amoenus or pleasant place tradition. The second one is that our thoughts are governed by our experiences and what for instance what I understand for a city is not the same idea from northern people. 2013_1_4 [journal written in English]

Students reported that the visits to museums and cultural centres had given them new perspectives and ideas related to multiculturalism and the cultural diversities present in their residential city. For many, these were the first visits to the cultural centres especially. The positive feedback and the various reflections suggest that these kinds of spaces could be used more in teacher education. 
When using the urban spaces for learning the potential encounters cannot be controlled similarly to the class room learning. Unpleasant experiences, such as facing expressions of hate, can occur in spontaneous interactions. One student reported on a negative incident on a street as follows:

One day I was walking down the street with a friend and we were talking in English with each other and when we passed a guy he suddenly said that we are in Finland and we should stop speaking English but Finnish. We were looking at each other and we were both confused and didn't know how to response to that. In my country you hear a lot about situations like that but I have never been confronted to it. I didn't know how to react I just felt uncomfortable and also a little bit angry. I think that this exchange semester have already changed me and some of my points of view because of being faced to situations and moments like that.2014_5_1 [journal written in English]

This surprising, confusing event had seemingly helped the plunger to reflect on wider issues and brought an emotional element to the learning process, thus reflecting Nieto's (2006) emphasis on the critical role of emotions in learning.

The limitations of the plunges can be related to the risk of isolated information and oversimplification, ethical concerns including objectification as well as issues related to power and responsibility (see Houser, 2008 and Nieto, 2006 for discussion). In our application of the plunges, students did not use false identities; attend small religious services or other intimate communities which would have raised strong ethical concerns. In turn, the fairly superficial encounters the students had may not have provided as strong experiences to stimulate reflection and learning.

Students' varying levels of engagement in the plunges is a point to consider when planning the implementation of the approach (Houser, 2008; Nieto, 2006). Not everyone gets as much out of the plunges, sometimes due to fears and concerns related to the task (Nieto, 2006). As King et al. (2013) emphasised the equal value of diverse approaches to intercultural experiences, it is critical to consider how to create spaces for diverse ways of engagement that can contribute to meaningful learning. In our study, the plunges assisted teacher students to recognise the need to discover one's own fundamental assumptions, values and biases and to discover their professional 
responsibility to reach out to diverse students. According to Nieto (2006), this level of learning cannot be reached with standard teaching methods.

\section{Discussion and Conclusion}

Students' experience of the plunges was generally reported as positive. However, as the reporting was done as part of a required learning journal, the negative attitudes may have been hidden (see Houser, 2008 for discussion). On the other hand, the generally positive student feedback from the course suggests that the plunges were appreciated as a learning experience. Also, to a large extent, teacher students stayed within or very close to their comfort zones which protected them from experiencing fear and discomfort reported by students in studies by Nieto (2006) and Houser (2008).

Teacher students used various approaches to learning during their plunges (see King et. al., 2013). In our study, students justified their choice of plunges mainly through practical reasons. They connected the plunges into their daily activities and used the task to see their everyday life from a different perspective. Some were more adventurous than others the other - for some, a visit to a new museum was a special event while others would casually tell about one week of couch surfing in a stranger's home. Similarly to King et al. (2013) we emphasise the quality of engagement rather than its type as critical to experiential intercultural learning.

One should be cautious to automatically link intercultural experiences to learning. Plunges may indeed support learning but they may also remain isolated events that may be fun or exciting but not result in significant intercultural learning experience. Also, if teacher students only do the plunges as they are a given assignment by the teacher, how do they become responsible over their learning? When intercultural experiences are used to enhance learning, the role of students becomes more active which then requires new approaches and skills from teacher educators. 
This present study reinforces the previous analysis of the value of cultural plunges in teacher education. The findings emphasise the need to expand the academic learning space beyond lecture halls in a systematic way. Plunges to diversities are essential to any future teacher as they can help to understand difference. While teaching practice in regular schools provides teacher students with 'real life learning' (see Riggio, Sapolis \& Chen, 2011) in a professional context, the plunges can contribute by adding a more personal, experiential element to intercultural learning outside the school context. The city can become an important silent partner in teacher education that can provide space and stimuli for reflecting on the intercultural. We suggest that more essential than the form of exposure to diversity is the reflection, sharing and understanding of the experience. To build upon the encouraging initial experiences with the plunges, pedagogical tools should be created to encourage teacher students' reflection on their intercultural experiences to enhance learning.

\section{References}

Baker, F. (1989). How can you have experiential learning without experiential teaching? Teacher Education Quarterly, 16, 35-43.

Dervin, F. \& Hahl, K. (2014). Developing a Portfolio of Intercultural Competences in Teacher Education: The Case of a Finnish International Programme. Scandinavian Journal of Educational Research, 59, 95-109.

Dervin, F. \& Keihäs, L. (2013). Johdanto uuteen kulttuurienväliseen viestintään ja kasvatukseen. Kasvatusalan tutkimuksia 63. Helsinki: Suomen kasvatustieteellinen seura.

Houser, N. O. (2008). Cultural plunge: a critical approach for multicultural development in teacher education. Race Ethnicity and Education, 11, 465-482.

King, P. M., Perez, R. J., \& Shim, W. J. (2013). How college students experience intercultural learning: Key features and approaches. Journal of Diversity in Higher Education, 6, 69-83. 
Middleton, S. (2014). Henri Lefebvre and Education. Space, history, theory. London and New York: Routledge.

Nieto, J. (2006). The cultural plunge: cultural immersion as a means of promoting self-awareness and cultural sensitivity among student teachers. Teacher Education Quarterly, 33,75-84.

Rauste-von Wright, M. (1997). Opettaja tienhaarassa: Konstruktivisimia käytännössä. Jyväskylä: Atena.

Riggio, M.C, Sapolis L. G. \& Chen, X. (2011). When the city is your classroom. Frontiers, 10, $171-194$.

Wilson, A. (1982). Cross-cultural experiential learning for teachers. Theory Into Practice, 21, 184-192. 